\title{
Features of geodetic maintenance for water supply projects in Azerbaijan
}

\author{
M.H.Gojamanov ${ }^{1, *}$, Ch.Z.Gurbanov ${ }^{1}$
}

1Baku State University, Z.Khalilov Street, Baku, Azerbaijan, AZ1148 - mgodja@yandex.ru, chgurbanov@mail.ru

\section{Commission V: WG V/3}

KEY WORDS: Water supply, Sewerage system, GIS, Programme support, Geodetic monitoring, Environment, Plan-height positioning

\begin{abstract}
Drinking water supply and sewerage system designing and reconstruction projects are being extensively conducted in Azerbaijan Republic. During implementation of such projects, collecting large amount of information about the area and detailed investigations are crucial. Joint use of the aerospace monitoring and GIS play an essential role for the studies of the impact of environmental factors, development of the analytical information systems and others, while achieving the reliable performance of the existing and designed major water supply pipelines, as well as construction and exploitation of the technical installations. With our participation the GIS has been created in "Azersu" OJSC that includes systematic database of the drinking water supply and sewerage system, and rain water networks to carry out necessary geo information analysis. The system software was developed based on "Microstation" platform, which identifies the coordinate system and cartographic projection along with the geo-referencing through direct connection to Google Earth platform.

Should be mentioned that, in the country, specifically in large cities (i.e. Baku, Ganja, Sumqait, etc.,) drinking water supply pipelines cross regions with different physico-geographical conditions, geo-morphological compositions and seismotectonics. Therefore, constant control of the plan-height positioning, geodetic measurements for the detailed examination of the dynamics, repetition of the geodetic measurements for certain time intervals, or in other words regular monitoring is very important. During geodetic monitoring using the GIS has special significance. Given that, collecting geodetic monitoring measurements of the main pipelines on the same coordinate system and processing these data on a single GIS system allows the implementation of overall assessment of plan-height state of major pipes.
\end{abstract}

\section{Introduction}

Sometimes the analysis of risk factors in the Geographic Information System (GIS) does not help in solving the problems of obtaining abundant information about any object, by then, visualize this information in a map.

For example, in the study of information about the number of accidents in main pipelines, road accidents, etc., we see that they are closely related to other factors: the presence of dangerous passages, uneven road surface, the intensity of transport, reduction of water pressure in the main pipelines, the temperature change in the atmosphere, the influence of anthropogenic and technogenic, exogenous and endogenous processes, some factors, depending on the morphology of the pipeline passing places. Visualization of accidents on the map makes it possible to describe the critical areas, which is important in preventing unwanted accidents, and making the right decisions. *

An essential resource for daily living, health, economic development and ecosystem means water. As it is too valuable, its delivery to the people in high quality assumes a very significant importance. Climate change, drought, water scarcity and increase number of people in rapidly growing world increases the burden on existing water resources. Hence, it can be concluded that, for conservation and rational management water resources, and reduce water losses, there is a need for taking constant necessary measures in direction to avoid losses.

\section{Main Water Pipeline System}

In Azerbaijan Republic, the uniqueness Oghuz-GabalaBaku water main of which length is more than $251 \mathrm{~km}$, is in the first place for its length, complexity and productivity. This main water supply system is one of the largest engineering facilities of the 21 st century. Evaluation pipelines risk factors affect during the operation of the existing main water pipelines should be considered as provision of security natural, technogenic and anthropogenic risk factors and pipe lines.

Carrying out monitoring researches in the areas through which water mains pass and that are prone to danger, and form Data Base (DB) at GIS platform is considered a very important setting. Duly assessment risk factors will lead to reduction natural-technogenic-anthropogenic impacts via absolute scientific justification. Application GIS technologies for absolutely conducting critical geodesic monitoring system, making decisions of their technical diagnostics and emergency situations in the direction of constant qualitative water supply at water pipes, timely prevention emergency events and reduction damage that may cause by accidents, is considered indispensable.

It should be noted that, at a time when large-scale infrastructure projects are carried out in our country, provision water pipelines security at water supply, routes that water mains pass covering different areas, is one the most important issues of numerous essential projects realized by "Azersu" OJSC. The indicator for protection their operational security is determination the category of risk and its assessment.

Water mains pipes safety shall be fulfilled considering several obligations. Beginning from projecting, construction and operational stages, regulatory requirements should be of great importance. In such cases, the usage of modern methods, modern diagnostic means, and geodesic monitoring system of the pipe

* Corresponding author 
shall be taken into account during projecting, construction and operational works.

Information basis for building spatial data models at GIS is real digital presentation (mode). Formation of computer technologies and information are divided into 2 parts: analogue and digital [6]. The main component of GIS means date base (DB) components. There are 2 types of these components: graphic and thematic.

The basis of graphic DB shall include acceptance topographic base, and thematic DB should contain mentioned topographic base related additional information which have to reflect spatial data, description of the territory provided by reports or scripts as information.

In order to ensure security and reliability of water mains, in the most complex places, the crossings with oil and gas pipes, highways and railways, river crossings, valley crossings, submarine passages or culverts may be indicated.

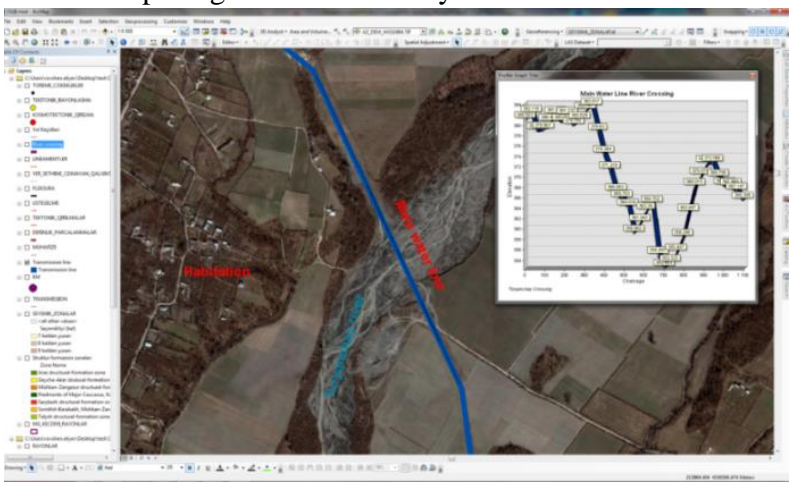

Figure 1. River crossing of water main

Just at the route figure 1,2 that Oghuz-Gabala-Baku water main pass, lies starting with water sources of Oghuz region to Baku city. The approximate $197 \mathrm{~km}$ of pipeline consists of CTP, and $53 \mathrm{~km}$ of iron (metal) pipes.

The number of river crossings is 12 and total length -5847 $\mathrm{m}$, highway crossings -10 and total length $-468 \mathrm{~m}$, crossings with oil and gas lines -4 and total length $80 \mathrm{~m}$, at $\mathrm{Km}$ $13,31,42,65,145,153$ and 216 areas drilling (split) ground works have been executed and volume is $500000 \mathrm{~m}^{3}$.

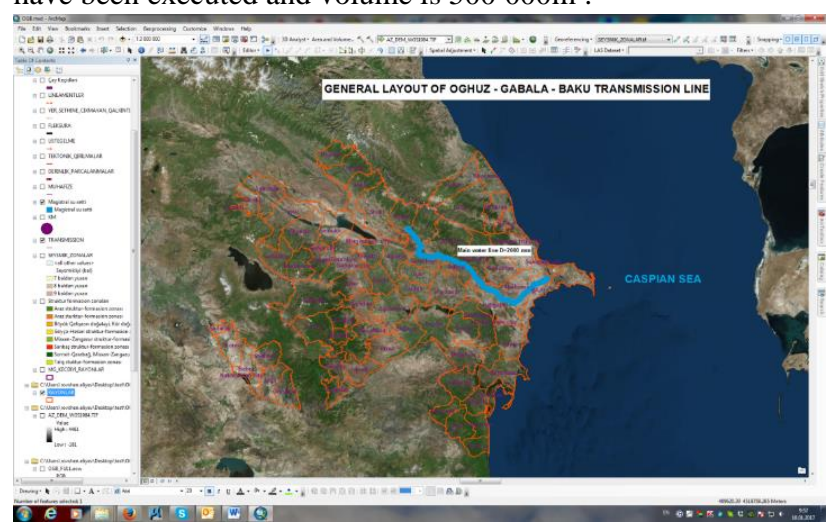

Figure 2. Oghuz-Gabala-Baku pipeline

Collecting information related to water pipelines analysis and monitoring of data reveal the need for placement at GIS (geographical Information System) platform the information as attribute data and coordinates of the incident, as well as zoning [12].

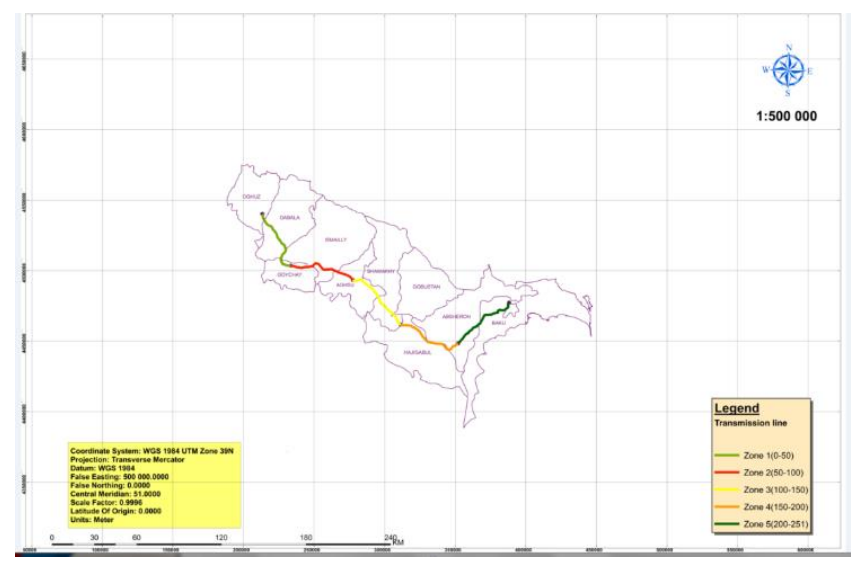

Figure3. Description of the pipe line with conventional signs

Under threat or risk factors mean potential loss (damage), which should be understood as the incident having impact on people, property or environment, as well as any event or condition beyond the control, and which results in accident and emergency situation [9].

Subject to engineering-geological condition, while evaluating security of water pipe operation, to know the progress of dynamical processes is very important. For avoidance such dangers, for evaluation strain is needed for soil changes due to various condition. In order to ensure security of operational pipeline and, solution the problem of geodesy monitoring, a data base should be set using GIS technologies. They have to contain the followings:

$\checkmark$ Determination pipeline in data base and information hereon;

$\checkmark$ Mutual relations for determined incidents;

$\checkmark$ Defining the main character of events kept by data base;

$\checkmark \quad$ Discovery the link between the characters of incidents occurred;

$\checkmark$ Completion the general schedule of all characters of the incidents, and logic scripts;

$\checkmark \quad$ Set of input and output data format.

If we look through the statistics of accidents that have occurred so far today we see that, the frequency of accidents at main pipelines of the same coordinates, takes place in the areas considered the most dangerous, and at which the highly dynamic cryopedology (freezing science) processes observed [7] and [11]. Assessment of risks at main pipelines by application GIS technologies is too significant: to determine the relief, running water, plants, seismic impacts and etc., and parameters of dangerous processes that may be formed around the pipeline. In order to achieve a secure supply of abuse will be required to establish the following models in the use of GIS [13].

- To distinguish district according to intensive formation natural man-made impacts along the pipeline,

- To specify identification and inventarisation of potential threats,

- To ensure complex ecological monitoring of compound natural-technical system,

- To analyze forecast assessment at backdrops of manmade, technogenic and natural effect.

All cartographic bases of listed events, including elements of pipeline, geodesy monitoring means, zones and digital models constitute the base information of geoinformation system. 
Assessment and management of risks means that, for avoidance undesirable accidents during exploitation of water mains, the practical action should be established so, that water supply could be duly controlled. Management is to determine the methods for reduction risk. To that end, the assessment may be as the following:

$>$ primary identification of danger;

$>$ description of the cause of danger;

$>$ analysis of risk probability;

$>$ full characteristics of quality and quantity parameters;

$>$ conduct statistics;

$>$ spread of information at scientific debates on risk incidents

For prediction the cause of accidents and emergency situations, usage of absolute information technologies, ensuring modelling, and basing on maximum precise prediction information, usage of digital maps related to the place of accident, for the purpose of flood, swamping zones, seismically active zones, landslide zones and etc., and taking into account other risk factors may be considered the principle [8] and [10].

\section{The Physical and Geographical Conditions of the area of Passing Main Transmissions Water Pipelines}

As seen from Figure (4-5) the Oguz-Gabala-Baku water pipeline passes through the region with different physicalgeographical conditions, geological - geomorphologic structure, seismic tectonic activity [1] and [14].

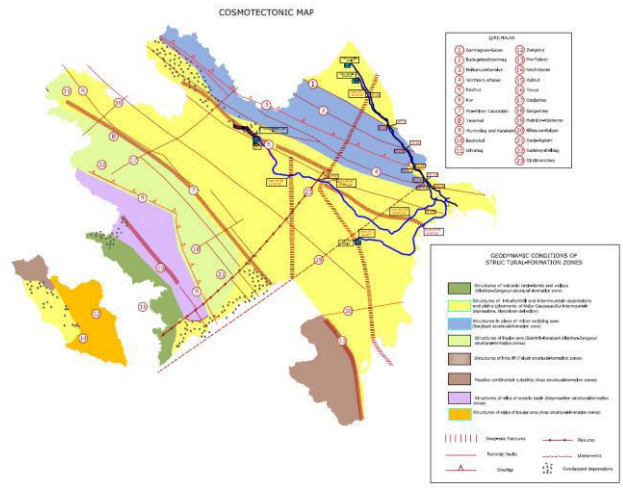

Figure 4. Physical-geographical conditions, geological geomorphologic structure map

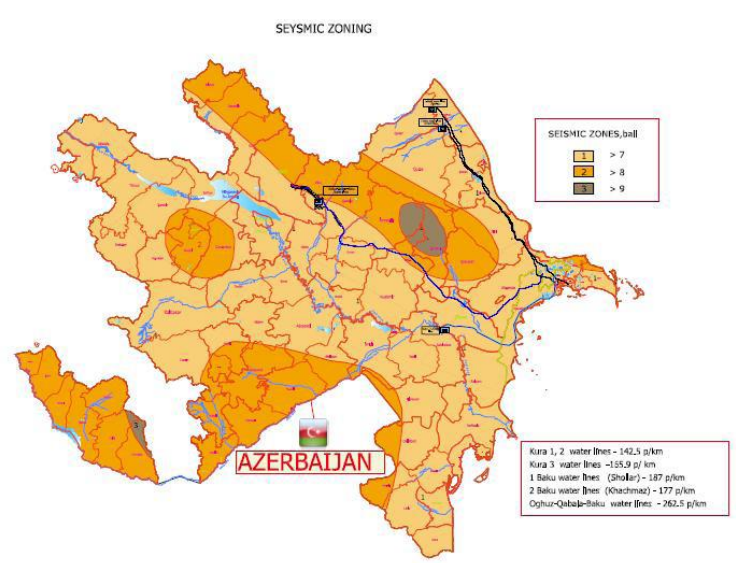

Figure 5. Seismic-tectonic activity map
During the operation of the water supply natural and technological system various types and sizes of disasters can occur and emergencies arise, the main reason of that is connected with interrelated influence of technological elements of the system and the natural environment. In many cases, this process takes place at background of a dynamic imbalance. This leads to the activation of dangerous natural and man-made processes. In turn, these processes affect the water supply plan-altitude conditions. As nature and technical systems are interrelated, the noted also affects environment, at result ecological environment, as well as socio-economic conditions deteriorate. Therefore, for the assessment of geo-ecological conditions of natural-technical system of main water pipelines, development of specific methods and techniques and on this basis the elimination or reduction of consequences of the accident, the necessity to develop appropriate technologies arises. This is the important and urgent evidence of conduction of monitoring in space-time size of the natural technical system of main water pipes as a whole.

The peculiarity of the project is that in its implementation the SCADA (Supervisory Control and Data Acquisition) system is used (Figure6). Note that the system applied for controlling of main water lines, water supply and sewerage systems from a unified center regulates online transfer of water from source to consumer. The volume of water in reservoirs by means of the system, working conditions of taps, the pressure available in reservoir exits and network, the reserve capacity of reservoirs are controlled automatically. At the same time, the geographical coordinates of the breakdown in the lines are recorded, promptly eliminating of the problem is provided.

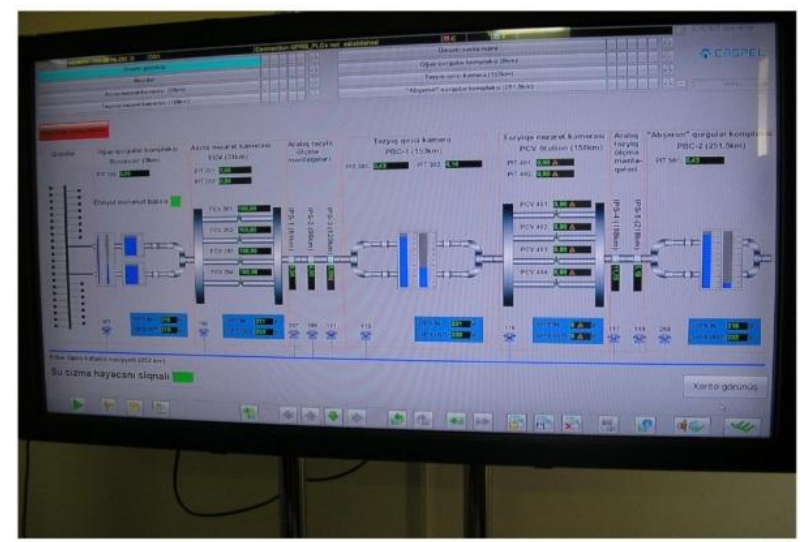

Figure 6. SCADA system main water pipelines

\section{Remote Sensing Method and Features of Geodetic Monitoring System}

Aerospace research methods and GIS technologies are to be used in complex in organization of information-analytical system and study of factors impacting the environment during reliable organization of operation of existing and designed water pipelines, construction and operation of technical structures. However, the analysis shows that the remote sensing survey data and the methods are not used effectively in addressing of these issues.

However, in the analysis of status of the plan of the linear structures of natural-technical system, through the increase of the efficiency of utilization of aerospace information, the possibilities to assist in execution of appropriate actions on mitigating the impact of negative events, which already took place or to warn about different possible hazardous emergencies. 
However, using the aerospace information to reveal the extraordinary events makes only the part of the monitoring process. At this stage, the areas where accidents took place or are likely to occur in water supply system. But at next stage testing areas are created in those areas and measurements are carried out on the definition of the conditions of plan-altitude and straightness of line with geodetic instruments.

In the modern conception the monitoring being a system of regular survey of status of nature and man-made objects and displacement dynamics based on the given program, besides revealing of events to be occurred, in advance, also consists of forecasting of emergencies (long-term and short-term or operational), as well as management system for taking actions in connection with possible emergency situations and its development [3] and [4]. Figure 7 shows block-diagram of geodetic monitoring system for the water supply pipelines in "Azersu" OJSC [2].

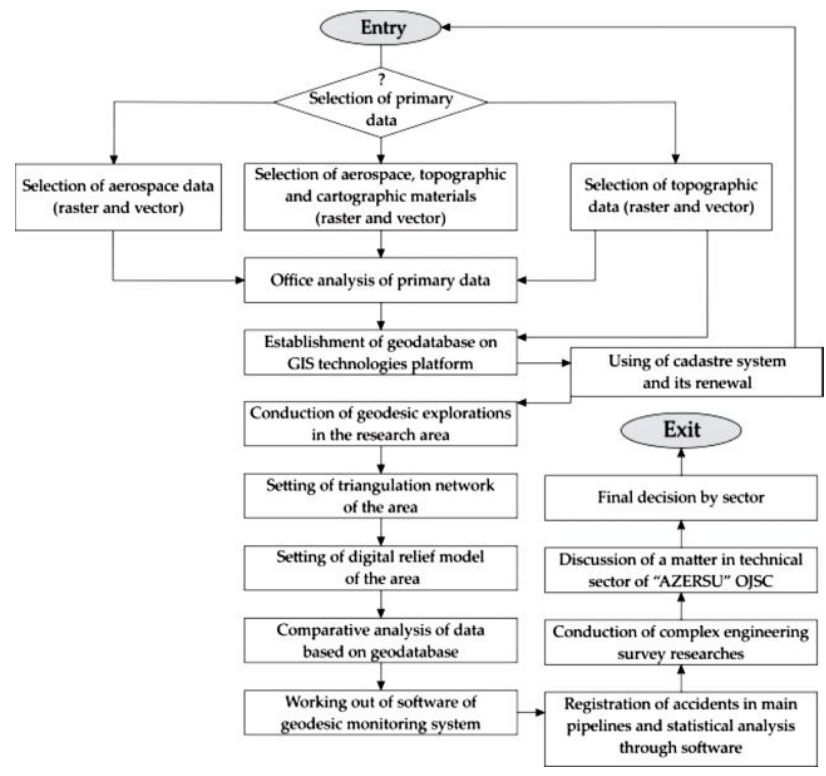

Figure 7. Geodetic block scheme of the monitoring system

GIS is of great importance in the organization of monitoring. On its basis the information related to monitoring of pipelines is collected, processed and stored. On the other hand the information obtained from another measuring means may be entered in the GIS and at result the new aerospace-geodetic monitoring system would have been created. And it plays an important role in implementation of comprehensive evaluation of plan-altitude condition of network of the main water supply pipeline and study of impact of water supply system on environment, as well as vice versa, that is the effects of natural processes to main lines. Therefore, developing of methods and methodologies for the study of reasons of occurrence of mutual impact between main water supply pipeline of "Azersu" OJSC and environment, complex evaluation of conditions of pipelines in respect of space time is of great importance. The following methods and technological schemes have been used to address issues from our side:

Thematic cartography, aerospace monitoring, analysis and tabulation methods to assess the balance of natural-terrain complexes;

Acquisition, collection, processing and decoding by visual and automatic methods of aerospace information for assessment of the dynamics of movement of natural-terrain complexes, as well as to forecast the balance in areas of passing of pipelines;

Creation of specific thematic maps for analysis of the natural terrain water supply system based on processing and interpretation of results of aerospace, geodesy-cartography materials;

Processing of space digit images with the help of ERDAS software and creation of databases along the pipeline for experimental areas;

Transforming of cartographic materials in vector format and processing with proper applied programs (such as ArcGIS or MapInfo);

Making the applied informative analytical GIS projects for individual areas, which require particular attention along the main pipeline;

Probability and analytical assessment of actual and potential dangerous conditions of main pipelines.

In modern times the size, scale and speed of changes in the environment as a result of anthropogenic impacts are so great that in a single moment of time to study these changes for large areas with surface methods is practically impossible. Therefore, from modern computer technology GIS technologies, joint using of cartographic methods and distant research techniques, i.e. their integration would be the most optimal and efficient modern approach in information and cartography provision for monitoring of eco-condition of the water supply system in the space-time scale.

It should be noted that the depreciation (deterioration) of engineering constructions is directly dependent on the speed of development of natural and natural-technological processes occurred in the areas of main pipelines, natural-technical system and location of this system. In particular, at result of interaction of main pipelines with the physical and geographical environment it leads to an acceleration of process of formation and growth of wetlands, formation of karsts and thermal karsts, ravines and surface soil erosion, cracks and etc events, which damage of pipelines. Therefore, during the monitoring of main pipelines the state of natural and man-made elements should be evaluated in a comprehensive manner [5].

\section{CONCLUSION}

The following conclusions and recommendations can be made on the presented study.

1. Theoretical and experimental studies have shown that in terms of the proposed geodesic monitoring system in the event of natural and man-made, as well as the assessment of the effects of man-made events possible.

2. Geodetic measurement results and a variety of GIS spatial data management based on an integrated platform, events that may occur, depending on the interaction between the environment and the main lines of the processes may allow the establishment of evaluation and forecasting models.

3. Using of geographic information systems is very important for designing of drinking water supply and sewerage systems, and collection of date necessary for it in a common information space and more accurate implementation of the project works.

4. The study of interactions between various elements is very important in designing of water supply pipeline system, the construction and operation. In this regard, we prepare special methods and algorithms for assessment of geo-ecological state of natural-technical system of water supply pipelines of 
"Azersu"OJSC, as well as the action plan is being developed on their basis to eliminate the consequences of the accident.

5. In general, study of natural environment factors impacting the current and projected water main pipelines, the geodetic monitoring measurements for effective organization of information-analytical system, aerospace research materials and complex use of geographic information systems is more purposeful.

\section{REFERENCES}

1. Gojamanov, M., Gurbanov, Ch., 2014. The features of the use of GIS technologies for monitoring of the situation of main water lines in Azerbaijan. In: The International Archives of the Photogrammetry, Remote Sensing and Spatial Information Sciences, Vol. XL-2, ISPRS Technical Commission II Symposium, 6-8 October 2014, Toronto, Canada, pp. 235-241.

2. Gurbanov, Ch., 2014. The creation of geodetic monitoring system in order to exploit water transmission lines. Journal of Qafqaz University - mechanical and industrial engineering, Vol. 2, number 2, pp. 142-148.

3. Gojamanov, M., 2006. Geodetic monitoring the location of the offshore objects. Hydrometeorology and environmental protection, Baku, Azerbaijan, No3, pp. 126-130 (in Russian).

4. Gojamanov, M., 2009. Geodetic maintenance and monitoring works at sea. Moscow-Baku, p.104 (in Russian).

5. Gojamanov M., Gurbanov, Ch., 2016. Geolocation support for water supply and sewerage projects in Azerbaijan. The International Archives of the Photogrammetry, Remote Sensing and Spatial Information Sciences, Volume XLI-B4, 2016, XXIII ISPRS Congress, 12-19 July 2016, Prague, Czech Republic, pp.777-781.

6. Khlebnikova T.A., 2007. Creation of digital maps and plans by means of GIS assets «Panorama»[Text] : Educational methodological manual / T.A. Khlebnikova. - Novosibirsk: SSGA. -125 p.

7. Struchkova G.P., Kapitonova T.A., Sleptsov O.I., 2011. Estimation of influence of exogenous processes in the oil and gas complex in the conditions of cryolite zone // Problems of safety and extreme situations. № 2. - p. 53-59.

8. Sleptsov O.I., Kapitonova T.A., Struchkova G.P.,2007. Simulation of emergency situations at transportation of hydrocarbon raw materials in the conditions of cryolite zone // Second All-Russian Conference «The Safety and Survivability of Technical Systems». - Krasnoyarsk,. - p. 88-91.

9. Sleptsov O.I., Levin A.I., Struchkova G.P., 2008. Safety of gas - extraction industry // "Social, economic and technological problems" in the book - Security of Sakha (Yakutia) Republic. - Novosibirsk: Nauka. 296 p.

10. Sleptsov O.I., Akovetskiy V.G., Struchkova G.P., 2004. To the question about safety management of main pipelines // Proceedings of the II Eurasian Symposium on the problems of strength of materials and machines for cold climate regions. Plenary reports. - Yakutsk,. pp. 220 - 223.

11. https://ru.wikipedia.org/wiki/

12. http://www.gkhprofi.ru/news.php?id=748

13. http://www.fundamental-

$\underline{\text { research.ru/ru/article/view? } \mathrm{id}=34032}$ 